\title{
OPPORTUNITIES AS EXISTING AND CREATED: A STUDY OF ENTREPRENEURS IN THE SWEDISH MOBILE INTERNET INDUSTRY
}

\author{
HENRIK BERGLUND \\ Department of Technology Management and Economics \\ Chalmers University of Technology \\ Sweden
}

\begin{abstract}
The notion of opportunities is fast becoming a central theme in the field of entrepreneurship research. As part of this growing interest, the ontological status of opportunities has been scrutinized with researchers tending to view them as either objectively existing or socially created. In the present treatment, this ontological debate is partly avoided in favor of a phenomenological examination of Mobile Internet entrepreneurs, which naturally bridges these distinctions. The empirical findings are used to propose a framework in which opportunities are seen as both existing and created in the evolving set of perceptions and projections, sometimes fixed and sometimes mutable, that provide the cognitive and practical drivers needed to guide entrepreneurial action.
\end{abstract}

\section{INTRODUCTION}

As entrepreneurship is almost reflexively acknowledged to be "the fundamental impulse that sets and keeps the capitalist engine in motion" (Schumpeter 1975: 82), researchers seek to delimit and establish a distinct field of inquiry that addresses specific issues not covered by other disciplines. In recent years these efforts have started to converge on the topic of entrepreneurial opportunities, as providing a unique and core concern of the entrepreneurship discipline (e.g. Bygrave and Hofer, 1991, Venkataraman, 1997, Van Gelderen, 2004). Intuitively the notion of opportunity seems congenial to entrepreneurship. Dictionary definitions speak of favorable circumstances and occasions for progress and advancement. But like any concept, opportunity can be interpreted in many different ways. These interpretations also have concrete implications, as various views of entrepreneurial opportunities ultimately enter into macroeconomic policy 
measures (Rothbard, 1992), education (Saks and Gaglio, 2002) and practical advice for acting entrepreneurs (DeTienne and Chandler, 2004). For the sake of both theoretical development and practical interventions, it is therefore important that discussions regarding opportunities remain open and constantly seek new scientific grounding.

In the literature, two broad perspectives on opportunities are beginning to emerge. The first endorses a realistic view where opportunities are seen as natural occurrences in the world that exist prior to being discovered by alert, skillful or fortunate entrepreneurs who then take actions to exploit them (cf. Kirzner, 1973, Drucker, 1985, Shane and Venkataraman, 2000). The second perspective instead suggests that opportunities should be thought of in the context of entrepreneurs seeking to create their ventures in a world which fundamentally depends on entrepreneurial imagination and action for its development. In this view, opportunities are not discovered before exploitation but rather enacted in creative and social processes (e.g. Shackle, 1979, Gartner et al, 1992, Sarasvathy, 2006).

A number of researchers have sought to reconcile these seemingly opposing perspectives, often by subsuming them under larger theoretical frameworks. Some draw on the psychological literature of creativity to argue that both discovery and creation are special cases of a more general process. Psychological models of creativity typically comprise five stages: preparation, incubation, insight, evaluation and elaboration (Csikszentmihalyi, 1996). This stage model is then used as a master framework that subsumes both discovery and creation (Lumpkin, Hills and Schrader, 2003). In a similar vein, Chiasson and Saunders (2005) use Giddens' structuration theory as a higher-order framework to discriminate between conceptualizations of opportunities, i.e. whether they emphasize recognition or formation of relevant 'structure-guided scripts'.

The present investigation also has a reconciliatory ambition but, instead of raising the theoretical level of abstraction, it draws on the phenomenological tradition to explore how opportunities are perceived and enacted by individual entrepreneurs as part of the venture creation process. To paraphrase the phenomenologist Alfred Schütz, the answer to the question 'What does opportunity mean for me the observer?' requires as a prerequisite the answering of the quite other question 'what does opportunity mean for the observed actor?' My general aim is consequently to investigate how entrepreneurs perceive opportunities, and then examine whether the apparent theoretical conflict between the discovery and creation perspectives is sustained when related to these experiences. 
To foreshadow the conclusions, it appears that entrepreneurs have a broad and multifaceted view of opportunities and regard them as both existing and created, depending on the context and ambitions to which they are related. Based on these findings, it is proposed that entrepreneurial opportunities should be understood in relation to entrepreneurial action. From this perspective their ontological status, i.e. whether they exist or not, is of lesser importance as the opportunity perceptions themselves provide cognitive and practical drivers or 'points of orientation' that more or less temporarily guide entrepreneurial actions.

The paper is structured as follows. The next section reviews the discovery and creation perspectives. The scope of the paper precludes a comprehensive treatment, so the review touches on some important economic precursors and then focuses on the central arguments of Scott Shane (2003) and Saras Sarasvathy (2006). Thereafter, the phenomenological method is introduced and elaborated in some detail. This is followed by a presentation of results, a discussion of the results in light of the theoretical perspectives, and a concluding elaboration of how opportunity perception can be conceived in relation to entrepreneurial action.

\section{TWO VIEWS ON ENTREPRENEURIAL OPPORTUNITIES}

Entrepreneurial opportunities have received much attention and, as mentioned in the introduction, two general perspectives are emerging: opportunities as existing before discovery and exploitation, and opportunities as created in social processes. Both perspectives are grounded in established economic traditions and have been elaborated over the years by a number of entrepreneurship scholars. For reasons of brevity and clarity, this review is mainly structured around the key arguments of Scott Shane and Saras Sarasvathy. This does not mean that earlier contributions are not acknowledged or that these authors have developed their ideas in theoretical isolation (cf. Herron and Sapiensa, 1992, Bhave, 1994, Venkataraman, 1997, Gaglio and Katz, 2001, Ardichvili et al. 2003). Instead, Shane and Sarasvathy are chosen because they explicitly advocate very distinct positions on issues such as the role of uncertainty, the intentionality of human action and the ontological status of opportunities. The use of Shane and Sarasvathy as exemplars also follows Chiasson and Saunders (2005) who use these authors to illustrate the extreme positions on their 'recognitionformation spectrum'. 
The reviews begin with each perspective's economic antecedents and a formal definition of entrepreneurial opportunity. The remainders of the reviews deal with the three main themes discussed in the writings of Shane (the sources of opportunities, enterprising individuals, and exploitation activities) and Sarasvathy (departing from the local, social rather than individual, and controlling rather than predicting) respectively. The review concludes with a summary of the main differences between the discovery and creation perspectives (Table 1).

\section{THE DISCOVERY PERSPECTIVE}

The discovery perspective can be traced to the Austrian economic tradition, and especially to Israel Kirzner's attempt to merge Mises' notion of the entrepreneur as the driving force of the economy with Hayek's ideas about knowledge distribution and spontaneous coordination. To Mises, entrepreneurship epitomized the distinctive feature of genuine human action, namely purposeful behavior based on subjective preferences and goals: "Ultimate ends are ultimately given, they are purely subjective, they differ with various people and with the same people at various moments in their lives" (Mises 1996: 95). Hayek was also a subjectivist and wrote extensively about the so-called knowledge problem in central planning, i.e. how planners are to obtain the knowledge required for successful planning (Hayek, 1937, 1945). Such knowledge is highly dispersed and typically incomplete, as it exists only in the minds and preferences of individual actors. Nevertheless, Hayek argued that the "tendency toward equilibrium is clearly an empirical proposition, that is, an assertion about what happens in the real world" (Hayek 1937: 44). In Kirzner's framework the Misesian entrepreneur is reified into an ideal type that embodies Hayek's coordinating tendency in society. Characterized by high levels of alertness, entrepreneurs are thus systematically "attracted to notice suboptimalities (constituting expressions of [Hayek's Knowledge Problem]) because they respond to the scent of pure profit which accompanies such suboptimalities" (Kirzner 1992: 174).

In entrepreneurship studies, the discovery perspective has been theoretically developed and empirically tested by numerous scholars. Some emphasize passive discovery of opportunities (Kaish and Gilad, 1991, Herron and Sapienza, 1992) including attempts to translate the alertness concept into specific psychological and cognitive properties (Gaglio and Katz, 2001; Baron, 2004). Others, leaning more on neoclassical econom- 
ics, focus on active search processes in the form of scanning (Drucker, 1985) or Bayesian learning where entrepreneurs systematically update their knowledge about the environment in pursuit of pre-existing opportunities (Fiet, 1996). The neoclassical view differs from Kirzner's emphasis on fortuitous discovery. Still, both traditions regard the development and existence of opportunities as unrelated to the entrepreneurs who discover them (Littlechild, 1986, Buchanan and Vanberg, 1991). This view of opportunities is succinctly summed up in the following:

"Entrepreneurial opportunities are those situations in which new goods, services, raw materials, and organization methods can be introduced and sold at greater than their cost of production. Although recognition of opportunities is a subjective process, the opportunities themselves are objective phenomena that are not known to all parties at all times." (Shane and Venkataraman 2000: 220; emphasis added) ${ }^{2}$.

\section{The Sources of Opportunities}

In elaborating the sources of opportunities, authors with a discovery perspective enlist the support of some of the most influential researchers in the field. Schumpeter (1961) saw technological inventions as the grist for innovators, but also listed political, social, regulatory and macroeconomic changes as sources of opportunities. Peter Drucker developed a similar taxonomy where entrepreneurial opportunities are seen to reside in seven broad sources of change: unexpected occurrences, incongruities, process needs, changes in industry structures or markets, demographic changes, changes in perception, and new knowledge (Drucker 1985, p. 35). As mentioned, Hayek (1945) saw opportunities as the result of the uneven distribution of knowledge in society, while Kirzner (1973) regarded alert discovery of arbitrage opportunities as the quintessential element of entrepreneurship. Opportunities are in this sense inefficiencies or "situations overlooked until now because of error" (Kirzner, 1985, p. 52). Opportunities thus exist objectively in the form of underused resources, different forms of structural change, and uneven distribution of knowledge which leads to unnoticed market inefficiencies. 


\section{Enterprising Individuals}

Even if opportunities exist autonomously, they are not equally visible to everyone. People have different access to relevant information about opportunities. Partly this is because some information is sophisticated and only understood by experts. More often, information about opportunities is of a mundane nature, e.g. noticing the price differences in two cities. Noticing such opportunities does not require expertise. Instead it is dependent on individuals' spatiotemporal location (Hayek 1945), relevant prior knowledge (Shane, 2000) and position in and between social networks (Burt, 2000). In addition to the heterogeneous access to information, entrepreneurs may differ in their entrepreneurial human capital (Schultz 1980), levels of alertness (Kaish and Gilad, 1991), and cognitive abilities to notice and evaluate opportunities given the same information (Busenitz and Barney, 1997). The discovery perspective thus comprises active and passive search as well as fortuitous discovery, since all three regard opportunities as existing 'out there' (cf. DeTienne and Chandler, 2004).

\section{Exploitation Activities}

Once the opportunity has been discovered and deemed worthwhile, the entrepreneur undertakes a series of exploitation activities. These include raising financial and other resources, protecting information about the opportunity from competitors, and designing appropriate organizations and business models (Shane, 2003). As mentioned, the world is unpredictable with respect to technology, markets and competitors. Therefore the entrepreneur will often craft strategies to deal with these uncertainties by introducing slack, identifying niche markets, forming strategic alliances, etc. (Shane, 2003). Careful planning is thus vital for successful exploitation of an opportunity, especially under conditions of high uncertainty (Delmar and Shane, 2003). Crafting a solid business plan helps the venture by evaluating conjectures about future events, focusing attention on bottlenecks and additional resource requirements, clarifying goals and objectives, and facilitating communication and increasing legitimacy in interaction with external stakeholders (Delmar and Shane, 2004). 
Opportunities as Existing and Created ...

\section{THE CREATION PERSPECTIVE}

The creation perspective can be traced to authors in the radical subjectivist tradition such as Shackle (1979) and Lachmann (1976). Radical subjectivists extend the Austrian notion of subjectivism from alertness and personal values, to explicitly include imagination and creative expectations about the future. The emphasis on creativity and the entrepreneur as a historymaker runs counter to both the neoclassical and Austrian frameworks. In these traditions, true knowledge of the future is seen to exist, albeit in dispersed, personal and tacit forms (Littlechild, 1986, Buchanan and Vanberg, 1991). To the radical subjectivists, such knowledge cannot exist because the future is yet to be created. Entrepreneurial action is thus making history instead of merely responding to it. This does not mean that entrepreneurs are completely unbounded in their creativity. On the contrary it is because actions are neither fully determined nor completely random that choice can occur. Knowledge and experience serve as inputs to imagination, but do not fully constrain or determine it. Entrepreneurial action is therefore genuinely creative, but within the bounds of imagination, leading to a definition of entrepreneurship as "action in pursuit of the imagined, deemed possible" (Shackle 1988: xi).

There has not been much research focusing explicitly on opportunity creation, but topics such as entrepreneurial enactment (Gartner et al, 1992, 2003) and entrepreneurship as a discursive practice (Steyaert and Katz, 2004) rest in part on a view of opportunities as socially negotiated and created. The creation perspective is most clearly promoted by Sarasvathy (e.g. Sarasvathy 2001, 2006) who views entrepreneurial opportunities as creatively developed in the everyday activities of individuals and groups. Sarasvathy's notion of effectuation echoes Shackle and the radical subjectivists while more clearly emphasizing the social dimensions of action. Starting with personal ambitions, limited resources and an open view to the future, the content, identity and direction of the opportunity are allowed to emerge as a result of implicit 'negotiations' with different stakeholders such as suppliers, partners and customers. The opportunity then emerges as a residual of this social process, thereby radically reducing the need for prediction. The creation position is concisely captured in the following:

"opportunities are a result of the efforts of particular entrepreneurs striving to construct corridors from their personal experiences to stable economic and sociological institutions that comprise organizations 
and markets we see in the world" (Sarasvathy 2004, p. 289; emphasis in original).

\section{Departing From the Local}

The creation view has been compared with the resource-based view of the firm, because it emphasizes what can be done with what is currently under control, rather than what should be done in order to reach a given position (Sarasvathy, 2001). This is in stark contrast to traditional definitions of entrepreneurship which emphasize the pursuit of opportunities regardless of resources (e.g. Stevenson and Jarillo, 1990). The 'resources' available to a prospective entrepreneur are highly personal and consist of imagination, identity, knowledge and personal networks (e.g. Johannisson 2000, Sarasvathy, 2001) as well as the ability to interpret the potential in one's cultural context (Lavoie, 1991). Starting from such local conditions, entrepreneurs develop their ventures in constant interaction with their local environment. The uncertain environment is turned into an advantage, since entrepreneurs treat serendipitous events and contingencies as opportunities to adapt and reconstruct their goals along the way (cf. Lindblom, 1959). This explains how early interactions with customers, partners or financiers can radically reshape the opportunity created. This should not be confused with Bayesian learning models of entrepreneurial opportunity search, where incremental actions and updated knowledge gradually lead entrepreneurs toward pre-existing opportunities (Fiet, 1996).

\section{Social Rather Than Individual}

An important aspect of opportunity creation is that entrepreneurship is not an individual endeavor (e.g. Gartner et al, 1994; Johannisson, 2000). When entrepreneurs leverage contingencies and enact their local environment, they more or less actively enlist the support and contributions of different stakeholders. In this sense the development of the venture is determined by a coalition that jointly defines what constitutes relevant goals, risks, markets and values (cf. Cyert and March, 1963). Lane and colleagues use complexity theory to make a similar point (Lane et al, 1996; Lane and Maxfield, 1996). They argue that in uncertain and rapidly changing situations there is limited room for traditional planning or maximizing behavior. A feasible strategy is instead to foster 'generative relationships' which provide the settings and collaborative milieus in which future opportunities may be developed (cf. Lane and Maxfield, 1996). In most ven- 
tures, the original imprint of the individual entrepreneur or founding team is typically quite pervasive (Nelson, 2003). Hellström et al. (2002) address this issue but argue that a more dynamic and social conceptualization of the innovating self adds nuance to the role of the individual. No matter where one locates agency and identity, the importance of assimilating external influences is critical to the creation of opportunities.

\section{Controlling Rather Than Predicting}

Sarasvathy (2001) sums up the logic of effectuation in a dictum: 'to the extent that you can control the future you do not have to predict it'. Experimental evidence also indicates that entrepreneurs typically believe that they can affect future events more than bankers can (Sarasvathy et al, 1998). By departing from local resources and contingencies, and gradually developing the venture through a social process of stakeholder involvement, the venture and its environment are, in a very real way, enacted (Weick, 1995). Social relationships and identity building are therefore not just an internal matter of steering the venture. Over time more and more customers, suppliers, partners, and regulators are involved in the venture process, which in turn leads to shared identities and commitments on higher levels (Simon, 1993). By being the first to do something, the entrepreneur sets the stage for potential followers and in effect creates the opportunity in the form of markets, standards, business models etc. (Sarasvathy, 2004).

Table 1. Differences between the Discovery and Creation Perspectives.

\begin{tabular}{|c|c|c|}
\hline & Discovery & Creation \\
\hline Basis in economics & $\begin{array}{l}\text { Neoclassical and Austrian } \\
\text { economics }\end{array}$ & Radical subjectivism \\
\hline $\begin{array}{l}\text { Ontological status } \\
\text { of opportunities }\end{array}$ & $\begin{array}{l}\text { Have real existence before } \\
\text { being discovered }\end{array}$ & $\begin{array}{l}\text { Are the emerging result of } \\
\text { a creative social process }\end{array}$ \\
\hline View of uncertainty & $\begin{array}{l}\text { Hides existing } \\
\text { opportunities }\end{array}$ & $\begin{array}{l}\text { Made irrelevant by } \\
\text { 'effectual' action }\end{array}$ \\
\hline Role of the individual & $\begin{array}{l}\text { Discoverer and exploiter } \\
\text { of opportunities }\end{array}$ & $\begin{array}{l}\text { Facilitator of creative } \\
\text { social processes }\end{array}$ \\
\hline Practical implications & $\begin{array}{l}\text { Individuals should pursue } \\
\text { promising industries and ideas, } \\
\text { staying focused on areas where } \\
\text { they are most likely to succeed }\end{array}$ & $\begin{array}{l}\text { Individuals should, together } \\
\text { with others, nurture exciting } \\
\text { ideas found in their } \\
\text { immediate environment }\end{array}$ \\
\hline
\end{tabular}




\section{METHODOLOGY}

\section{The Interpretive Phenomenological Method}

This study uses a phenomenological method to investigate how entrepreneurs experience and perceive opportunities. Since this is a rare approach in entrepreneurship research, the description of methodological procedure is preceded by a brief introduction of some underlying assumptions.

As a philosophical movement, phenomenology focuses on how phenomena are immediately and pre-theoretically experienced. This means that phenomenologists take a neutral position on issues regarding nature, culture or the individual as the ultimate source of experiences (MerleauPonty, 2002). Phenomenology has also developed into a set of descriptive methods that seek to outline the meaning of human experiences in a structured manner (Giorgi, 1985). This study employs a version of interpretive phenomenological analysis (cf. Smith, 1996). Interpretive phenomenology assumes that respondents' responses must be interpreted in order to reach the experienced phenomenon. The respondent's speech and actions are not assumed to mirror phenomena directly, as supposed by positivists. Nor are they assumed to constitute phenomena as argued by social constructionists. Instead the researcher must interpret the subjects' responses in order to glean their relevance for the phenomenon under investigation. The assumption is that what respondents say as they are interviewed has some ongoing significance for them and that there is a relation, though not transparent, between what is said and the underlying beliefs and assumptions they sustain (Smith, 1996).

Phenomenological methods have traditionally been used in fields such as pedagogy (van Manen, 1990) and nursing (Benner, 1994) where researchers' and practitioners' concerns are permeated by a deep interest in the subjective experiences of their subjects. Heterogeneity regarding motivations, experiences, skills and cognitive capacities is fast becoming a central theoretical assumption in entrepreneurship research (e.g. Davidsson 2004: 22). Phenomenological methods may therefore contribute useful insights also in this field (Berglund, 2007).

The methodological focus on personal experiences means that the present study cannot provide a verdict regarding the ontological status of opportunities. The goal is instead to examine how the two perspectives, opportunities as existing and created, resonate with the lived experiences of a group of entrepreneurs. The result of this comparison is then discussed in terms of how opportunity perceptions relate to entrepreneurial action. 
Opportunities as Existing and Created ...

\section{Participants}

Interviews were conducted with 19 founding entrepreneurs who, alone or together with others, founded new firms in the Swedish mobile Internet industry between the years 1998 and 2000 . These entrepreneurs were randomly chosen from a set consisting of about $80 \%$ of the mobile Internet firms started during this period. A firm was included in the set if the business idea fit the following description: 'to develop infrastructure that enables access to information and services that are distributed via the Internet and thereby makes information and services available regardless of time and place'.

\section{Interviewing}

The entrepreneurs were interviewed during spring 2002 at home or in their firms. The interviews lasted on average between one and two hours. In some cases interviews were followed up with telephone conversations to clarify specific details. The interviews were conducted by a group connected with the larger research project, and were preceded by a joint review of interview technique and discussions regarding content. As a result of these discussions, the group decided to conduct semi-structured interviews based on three broad themes: (1) What did you initially see as the way to make a profit, i.e. what was the business opportunity? (2) What do you see as the way to make a profit today, alt. What did you see as the way to make a profit when you went out of business? (3) If there was a change between 1 and 2, why do you believe such a change took place? Based on these broad questions, the entrepreneurs were encouraged to elaborate freely. The initial interviews were conducted jointly by the whole group. In this way the interviewers were able to establish a level of interpretive flexibility regarding how opportunity could be understood in the interview situations. It also established a coherent procedure by which to conduct the interviews.

\section{Analysis Procedure}

All interviews were taped and transcribed verbatim. They were then emailed to the interviewees in order to avoid any misunderstandings. The final protocols were then re-read by the author and the interviewers or transcriber. This allowed a coherent understanding of all individual proto- 
cols and afforded an opportunity to further scrutinize specific details in the transcriptions.

The individual interview protocols were then merged into a superdocument containing all the interviews. The transcripts were then analyzed by the author, line-by-line, in a procedure where the text was broken down into individual chunks or 'meaning units' (Giorgi, 1985). A meaning unit is a coherent expression of meaning which can consist of a sentence, part of a sentence or many connected sentences, but which is not limited by syntactic rules. A new meaning unit thus starts when there is a visible change of meaning in the text.

When the whole text had been broken down in this way, the resulting list of meaning units was re-read and discussed in the project group. As the researchers worked their way through the list, meaning units were cut out of the original document and pasted into a new document with a tentative category heading. Each new meaning unit on the list was similarly either put in an existing category or given its own new category heading. This process generated a great number of categories and during the process some categories, which were found to be similar, were merged and others split up - until all meaning units had been clustered into 20 categories that were agreed to capture specific homogeneous qualities of what was said by the participants. Overall there were no major disagreements regarding the content of the categories. The resulting categories were then reexamined and focused on in more detail. This resulted in six higher-order factors that contained related categories. The result was a hierarchy of empirical categories and higher-order factors that illustrate how opportunities were experienced by the interviewed entrepreneurs (see Table 2).

\section{Limitations}

There are some potential limitations to the present study. The ventures were started between two and four years before the interviews. At the time of the interviews, some of the ventures had recently failed, with an additional few failing after the interviews took place. While avoiding a common bias in the entrepreneurship literature of only investigating successful cases after completion (Davidsson, 2004), this also introduces a risk of retrospective bias.

The general fervor and excitement of the Swedish mobile Internet industry at the turn of the millennium (cf. "The Race to Rule Mobile", 2000; "Shining Stockholm", 2000) makes it an interesting setting for exploring how opportunities are perceived. The narrow focus also introduces a po- 
tential bias as the results may not reflect the experiences of other groups, notably less dynamic industries. In the present sample there may also exist relevant sub-groups of entrepreneurs based on critical experiences, psychological profiles or other contingencies. One may also argue that each individual entrepreneur experiences opportunities differently, and that the present study sacrifices too much of the complexities in the individual cases (e.g. Stake, 1994). Methods should be evaluated in relation to their intended purpose. The present study examines how entrepreneurs perceive opportunities by examining the experiences of a limited group. The findings of this study are therefore general to the extent that they prove useful in articulating the experiences of other entrepreneurs and improve understanding of opportunities as a theoretical phenomenon.

\section{RESULTS}

In the following section the results of the empirical study are presented. All categories contain input from multiple respondents. Consequently the categories and factors do not describe the opportunities or strategies of individual entrepreneurs, but represent a thematic structure of how this group of entrepreneurs experienced opportunities as part of the venture creation and development process (see Table 2).

Table 2. Opportunity Categories and Factors.

\begin{tabular}{|l|l|}
\hline Factors & Categories \\
\hline \multirow{3}{*}{ Exploiting knowledge } & $\begin{array}{l}\text { Passive expertise } \\
\text { Opportunity in the technology } \\
\text { Knowing and affecting the customer }\end{array}$ \\
\hline \multirow{3}{*}{ Filling the gap } & $\begin{array}{l}\text { Incorporating the market perspective } \\
\text { Imitation of concept } \\
\text { Distribution }\end{array}$ \\
\hline \multirow{3}{*}{ Enacting the Zeitgeist } & $\begin{array}{l}\text { Timing specific events } \\
\text { The system fails to deliver } \\
\text { Industry maturity }\end{array}$ \\
\hline \multirow{3}{*}{ Stability as strategy } & $\begin{array}{l}\text { Megatrends } \\
\text { Meta-opportunities in the hype itself } \\
\text { Prior business acumen }\end{array}$ \\
\hline & $\begin{array}{l}\text { Personal excitement as validation } \\
\text { Sequential entry process }\end{array}$ \\
& $\begin{array}{l}\text { Simplicity and clarity } \\
\text { Creating real value } \\
\text { Industry slump as threat and opportunity }\end{array}$ \\
\hline & $\begin{array}{l}\text { Consultancy as entry point } \\
\text { Develop and extend a strategic position } \\
\text { Take an early position }\end{array}$ \\
& Open-ended business model \\
\hline
\end{tabular}




\section{Exploiting Knowledge}

In this factor, opportunities are rooted in the entrepreneurs' specific knowledge or believed specific knowledge, regarding things like basic technologies and customer behaviors. The first category, passive expertise, illustrates how individuals with expert knowledge sometime rather submissively enter into business: "The background to everything was that $\mathrm{NN}$, our CEO, was a professor and led a research group at [university] on mobile informatics." Others were more clearly drawn forth on the basis of their expertise: "There would be large firms calling us up before Comdex and saying: 'we have nothing new to show, can't you come up with something', and we would."

Opportunity in the technology also builds on special competence, but focuses less on individuals' expert knowledge per se and more on opportunities perceived to reside in the technologies themselves, either by virtue of their inherent development potential or in combination with other technologies. One interviewee reports seeing the potential in the basic technology: "We started to attack more fundamental problems; the whole technology. And then we could also sell the infrastructure to operators." Others saw opportunities in combining technologies such as data communication protocols: "The mobile telephone can already handle SMS, so we built a converting box between WAP and SMS, without either the service side or content providers having to change anything. You didn't have to know whether it was WAP or SMS." Or similarly: "Making content services has been complicated before. We said, let them not have to do it in an SMS environment, let them write regular HTML like you do with an ordinary web page."

The value of detailed knowledge was also manifest in terms of the ability of knowing and affecting the customer. Such insight can manifest itself in a prudent approach to technological potential: "They did pure WAP stuff, but we said never mind WAP and WAP phones. Everyone has SMS phones and will have for the foreseeable future. Or if they have WAP functionality they are used to using SMS. Let them keep doing that." Or more generally: "What you can do is take the existing behavior and start with that, and create new services that fit the basic behavior that exists." The respondents also acknowledged the existence of behavioral inertia, as indicated by the following response: "You have to be aware of that when you develop products or develop a new market, it takes much longer than you think. If you also have to develop a new form of behavior...then you have a huge challenge." 
Opportunities as Existing and Created ...

\section{Filling the Gap}

This factor comprises three categories that show opportunities to emerge in missing pieces of different kinds of perceived frameworks. This is most generally indicated by the category incorporating the market perspective where market needs were either actively identified or reported to entrepreneurs by potential customers. One respondent described identifying his market thus: "We wanted mainly volume-based transaction revenues. Since the travel business, as industry or market, generates a large amount of transactions...there we identified, relatively early, large volumes and transactions in bookings and tickets." Another entrepreneur described learning about the market as follows: "We worked and talked to the ITdepartment, the telephone department. By talking to those people you know their needs. That has been with us from the start." Others report being more or less told what to do: "The customers have said, "solve that because it is important, only that'. Only fast telephone conferencing. Solve the group's needs." The pervasive significance of departing from a market perspective was described by one entrepreneur: "Think only of customers and markets. The technical will never be a problem in this country."

The category imitation of concept refers broadly to situations where entrepreneurs see gains to be made from taking a concept which exists and has proven to work in one place, and introducing it somewhere else. This can take many shapes. One entrepreneur reports how he had to leave his firm, after which he started operations with a similar focus: "In the beginning it was the idea of delivering Wireless Internet. No one did it then...or we came from the company that did it first - [Company name]. But we quit for different reasons and started [Company name]." Another interviewee reported a similar but less technologically oriented move where the original business concept was scaled down: "What we did was that we took the entire concept from a large firm to a small setting, including the idea of making complete solutions." Other respondents referred to imitation between different geographical markets: "I worked at [Company name]. We looked very much at what happened in Japan, especially service development. And then one looked at where the Swedish market was going. This was not discussed, it wasn't on the agendas of mobile operators. So it was from that perspective...to see, from what happened in Japan, the opportunities in selling services other than voice. That was the main opportunity, to go in early on and become the best on the Swedish market." 
Here the possibilities lie in providing value by taking advantage of specific conditions in the distribution part of existing or emerging value chains. One such strategy was reflected in the following statement: "SMHI [the Swedish Meteorological and Hydrological Institute] has a brand for the weather, while the operators have strong distribution and the possibility to charge customers. So they need each other in a way." Another entrepreneur mentioned partnering up with a large player as the most important source of unique distributive advantages: "This is a possibility we got when Telia [large telecom operator] became our main owner. We got a customer relation with about 700,000 customers, so we have a very large potential. This allowed us to use cash cards to reach customers."

\section{Opportunity in Timing}

This factor relates opportunities to questions of synchronization and timing. The extreme fluctuations in the mobile Internet industry show that timing is indeed important, with regard both to specific factors such as availability of capital and to the general maturity of the industry. Many entrepreneurs pointed out how timing specific events was the key to success or, more commonly, a source of problems in pursuing a perceived opportunity. In describing the failed introduction of a product, one entrepreneur describes the reason in this way: "There were some other elements missing in this chain...to configure a telephone for WAP simply wasn't very attractive. In those days there was no GPRS either." Another respondent pointed out as a bottleneck the lack of ability among operators to make use of differentiated debiting: "It has come now, but didn't exist then. We had far too poor debiting possibilities, which is the main reason it has taken time for us to develop better services." One respondent concluded that their timing was so far off that they had to discontinue their efforts: "We realized that we could not wait for the chain of WAP components to fall in place. [...] So what we did after about a year was that we abandoned this."

This category refers to the overall industry maturity and how the pace of developments in the whole structure of the mobile Internet industry taken together affected conditions for business positively and negatively. One person purports to describe the most important change in the last few years: "What has changed is mainly the market conditions, the level of consumer maturity and the costs of development as compared with the incomes generated." While all these things are connected, one respondent pointed specifically to the technology: "The maturity of customers and the 
industry depends on a host of things. For instance, communications are faster, we have better terminals and hand-held units are better." Yet others speak about how mobile Internet firms are typically ignorant as to their intimate relationship with the overall industry development: "You want so much in this Internet bubble...this mobile Internet. What you forget is that everyone working with something is so darn far ahead of the large mass of people."

The system fails to deliver refers to the opportunities that appear when there is a bottleneck in some part of a given industry system. Often the large players or conglomerates set the agenda by identifying and promoting markets and needs, but somehow fail to reach them: "It soon became clear that Ericsson, Nokia and Motorola were not going to be able to meet the demand for applications that will exist." And similarly: "We built an infrastructure component, which in fact also Ericsson and Nokia were doing, but they were slower. So we built an infrastructure component named $\mathrm{NN}$ and made it safe."

\section{Enacting the Zeitgeist}

Many entrepreneurs saw the emerging industry of mobile Internet as something relatively vague but inevitable, and often venture initiation was related to emerging and converging megatrends. One respondent said: "The underlying need is always there, that you want to be mobile with the same services. It is there." Or similarly: "I believe the world will be more mobile... if you just look at the explosion in mobile telephony, more types of services will be required. That's how I saw it...personally." Others had somewhat more precise ideas regarding the values they would provide: "It is a sort of time saver and increased freedom or whatever you want to call it. And that is what we have built the case around." Or: "You can say that the thought was to sell services based on group communication."

In the ferment of the mobile Internet industry, some entrepreneurs saw meta-opportunities in the hype itself. The specific idea or business model in itself was secondary, since the opportunity to start a business was seen as very attractive and viable in its own right. One repeat entrepreneur, who had not been working for a while, reports how he started to consider a new venture: "It hit me, the incredible amounts of money that went into 3G technology, and these firms didn't have a clue how to reach a market." Many respondents were rather clear about the importance of the hype for the decision to launch their ventures. As one entrepreneur stated: "What started our operations really...there was a pretty intense hype right then 
around mobile Internet, especially around WAP." Or as one interviewee acknowledged: "Let's face it, without the time that it was, we would never have been allowed to start it. It was enough of a hype to start a consultancy firm, which it wasn't later. So it was really only because of that, a low threshold for us to start." With such an environment, the business plans did not have to be very sophisticated, as indicated by this respondent: "The idea to the firm was that we had seen the second version of palm pilots, palm pilot pro before palm pilot three... around 1998 some time. And we figured 'Hey, we can do something fun with hand-held terminals'...so that is how advanced the business model was at first. We wanted to do something fun with hand-held computers."

Sometimes the background was neither specifically technological nor market-oriented. In the hyped-up situation, possessing prior business acumen often motivated people to get into business. Business acumen can be seen as a specialized competence of sorts, but it refers more to a general grasp of the start-up and financing situations, as indicated by the following: "What we saw... I worked quite a lot with these things at Andersen Consulting, and felt that we could get up and running fairly quickly. We understood a lot compared to very many others," and similarly: "Before starting [company name] I did some due diligence work for some VC companies." And: "When I worked at Ericsson I worked with investor relations, so I represented Ericsson toward analysts and the market, so I met a lot of market analysts."

In a hectic situation rife with uncertainty and novelty, some entrepreneurs referred to themselves as interpreters of the Zeitgeist, relying on the sense of personal excitement as validation. One interviewee reported: "The application was...we ourselves thought...we really used it a lot ourselves. It is pretty easy to make a product and then you notice that you do not think it is interesting yourself. But once we got it going we used it a lot." Another entrepreneur speaks of a similar sense of personal excitement: "You get so into what you do...like phone ring tunes. [...] It is so cool to get the phone to sound different, cool graphics on a screen...to get the weather report in your phone. We thought it was really freaking cool what we did."

\section{Stability as Strategy}

Many respondents clearly recognized the value of simplicity and clarity in developing their ventures. One respondent saw the future in terms of steady and incremental growth: "We are really just trying to maintain what 
we have and grow nice and slow. You shouldn't create any problems, so to speak...now if we expand these areas we will do it one per quarter or one every six months, so you build them and let them sink in." Others anchored their strategy in the employees, as indicated by one respondent: "The changes in business were always a way of trying to find a working business model for the personnel we had." A robust and straightforward business idea could also be seen as a source of stability: "We focus on security and believe that people are ready to pay for security...or security products. It sounds so simple...", or as another respondent put it: "We build simple applications."

The statements in the category creating real value cut through much of the hype and excitement, and instead maintained a clear focus on what was perceived to be of immediate value to customers. One entrepreneur reflected on how his offer differed from those of many other firms: "You can say that many of the services that were rolled out should not even be called services. The concept of service means that you provide a service to someone. It is not only creating a function; someone must adopt it and value it positively. Then it becomes a service...if you are ready to pay for it. Otherwise it is perhaps a function that may be interesting, but it is not a service." Another respondent emphasized the end product as opposed to the technologies used to create it: "We used a lot of existing technologies to solve common problems or improve things...that cuts costs, and that is what is being rewarded in the market."

When the initially booming mobile Internet industry came to a halt, this naturally affected the nature and quality of business opportunities perceived as feasible. The factor industry slump as threat and opportunity refers to the dual ways a market downturn can affect opportunities. Many factors combined to produce a generally negative spiral, something which affected many ventures: "Since the market crashed so quickly, everything is postponed. Partly because there is no money today, because of $3 \mathrm{G}$ licenses and psychological effects in the market that this is all crap, and because the capital financing of these companies is also gone." However, for those entrepreneurs who can and will hold out, an industry-wide slump may create new opportunities, as indicated by the following statement: "The IT boom hinged on advertising revenues. Then advertisers started to pull out...so the amount of advertising is down all in all compared to 2-3 years ago, but the number of places to advertise on is down even more, so there is still money to be made there." 


\section{Sequential Entry Process}

Many of the entrepreneurs worked as consultants before deciding to launch more specific offers. Some were rather specific about the strategy of using the consultancy as entry point, as evidenced by the following statement: "There were very few implementations with clear income streams, and the only way to make money really was to work as a consultant...to take consultancy jobs and bring in money by the hour," and: "The consultancy part we had was more business consultancy, but we also had a bunch of applications... with a platform that we tried to sell. So that was the next step." Another respondent mentioned how they started in consulting and also returned to consulting when the market went down: "Then when we cut down on the company, it was more business consulting. We knew those things then, because we had three years' experience and three years of business contacts. Then we worked more as business coaches, consultants and negotiators with the clients we worked with." Here, consultancy was both a relatively safe starting point and a means of gaining new knowledge and experience.

Another way to approach the future was to develop and extend a strategic position. Some entrepreneurs tapped into specific user needs to gain broad access to customers: "We have used public surf zones as a marketing tool to sell company accesses and also to households - use of these zones are part of the deal." Another entrepreneur in the general area of mobile security described his strategy for market penetration thus: "Develop a customer base [of GPS users], get customer relations through the installed base and exploit them to make money on services of different kinds." One respondent emphasized that to develop in a new market, learning from repeated and detailed industry interaction provides benefits both directly to the entrepreneur and in terms of marketing: "It is extra profitable to work in a vertically integrated segment. First of all you learn the specific parameters common to that segment, and secondly, if you have dealt successfully with one customer, the new customer must look at that experience - what the others have done. If he doesn't, he is not doing his job. There are advantages that he cannot incorporate in any other way." A more or less outspoken strategy was to take an early position vis-à-vis technologies or customers, then wait and hope for that position to become lucrative. As one respondent said: "But we saw that this is an area around which we want to create our knowledge, in order to be able to sell that knowledge when it takes off." One group started consulting to position themselves for the future: "We tried to land this, use the knowledge we 
have... In a smaller consultancy firm you can charge less and get the ball rolling. And then you are on the track until it starts rolling even more." The clearest options reasoning was displayed by the following entrepreneur: "Everyone believed in this, they thought it would come. We realized that if one positions oneself now, one will surely be in a good position later."

Many entrepreneurs talked about how market changes, partners, technologies, financing situation etc. forced changes in the business and revenue models. Since the industry was quite turbulent, an open-ended business model was seen as important. This is well illustrated by the following quotation: "Of course other stuff has popped up on the side, so the business plan has changed its appearance depending on the market," or similarly: "You have to be very clear about it, you always have to know what you make money on and then reroute the business model accordingly." The brute force of a turbulent environment was also indicated by an entrepreneur who admitted that: "The market forces...the surroundings force you to be even more focused on what is applicable in the here and now. There is no use in thinking about what might work in three to four years."

\section{DISCUSSION}

In this section the empirical factors are revisited and discussed in the light of the two theoretical perspectives of opportunities as created and discovered. The results are used here to elaborate the received theories of entrepreneurial opportunities. This is not to suggest that the results are general or that these factors make it possible to discriminate between theories. Instead the goal is to discuss how the experiences of this group of entrepreneurs compare with received theories, and on this basis to suggest a comprehensive way of theorizing about entrepreneurial opportunities that incorporates these findings.

A large part of the literature emphasizes the importance of exploiting knowledge in different ways. In the material, knowledge was sometimes applied rather directly to evaluate technological feasibilities or develop products and services. In connecting technologies, such as WAP with SMS, the entrepreneurs also exploited what may be seen as rather clearly existing opportunities (Kirzner, 1973). It was also shown that important knowledge can be based on knowledge of customers as cultural and historical actors. Opportunity recognition then is a matter of cultural interpretation (Lavoie, 1991) and opportunities can be exploited by nurturing and 
developing existing and emerging customer behaviors. However, there were other ways in which knowledge led to entrepreneurial opportunities and the decision to start a venture. The very presence of attractive and expert knowledge was sometimes 'exploited' in a passive sense, such as when a research group became formalized into a business venture (cf. Johannisson, 2000) or when external actors pulled the expert entrepreneur in different directions. This highlights the social nature of the opportunity development process, and plays down the typical role of the entrepreneur as actively in charge.

Filling the gap refers generally to viewing opportunities as gaps in larger systems or structures, e.g. a given market, a value chain, or a system of complementary products and services to be rolled out. The very existence of such structures is the prerequisite for gaps which are then filled, either through the development of a product or by adapting an existing solution to fit the gap. This lends credence to the idea of theorizing entrepreneurial opportunities as exogeneously existing (Shane 2003) and exploitable through arbitrage (Kirzner, 1973). The way the gaps are identified and especially enacted tend, however, to differ from the typically clear-cut notion of arbitrage. A structural gap often represents a rather vague opportunity which does not lend itself to net present value calculations. Typically a gap is coupled with creative ideas regarding how to fill it through networking activities (Johannisson, 2000), modification of the original offer, or promotion of a product or service in new markets by using novel organizational forms (cf. Schumpeter, 1961).

Opportunity in timing is similar to the previous factor in that respondents emphasize the opportunity context. Here, however, opportunities are seen as a result of the temporally uncoordinated and multilayered character of entrepreneurial processes, i.e. consisting of multiple trajectories with asynchronous development tempos. Changes over time in these trajectories will open and close different windows of opportunity. Such temporally generated opportunities can be more or less precise depending on whether they relate to the general maturity of industries and customers, or the development pace of specific technical components. Still, they conform to the discovery perspective in that opportunities are seen to exist independently of the individual entrepreneur.

The study also revealed that the temporal changes not only produced opportunities 'in themselves', but also became relevant in terms of how these fluctuations were perceived - e.g. entrepreneurs misinterpreting customer needs by developing products for the far future. In fast-paced and emerging industries like mobile Internet, there is a risk of getting caught 
up in an asynchronous time-bubble that is shared by other industry insiders. From a discovery perspective, this may be interpreted as entrepreneurs either under- or overestimating existing opportunities, by not synchronizing their own efforts with those of customers, partners or complementary industries (Shane, 2003). Authors with a social and creative bent may instead see such bubbles as an unavoidable consequence of the entrepreneurial process, and point to the fact that all opportunities exist against a backdrop of shared interpretations (Stayeaert and Katz, 2004).

While opportunities were often seen as emanating from the interrelated changes in technologies, institutions and social behavior (Schumpeter 1961), they were seldom seen in terms of specific products, profits or clear market needs. Instead, enacting the Zeitgeist describes how opportunities were indirectly related to such changes, or to the hype these changes generated. The entrepreneurs often started their ventures with a very general idea, combined with a believed ability to affect and control the future (Sarasvathy et al, 1998). Opportunities were generally conceived against the backdrop of pervasive megatrends and macro-changes (Drucker 1985), which were only loosely coupled to a perceived ability to create profits. As a consequence, the Zeitgeist was also seen to contain opportunities in and of itself. In a situation where traditional methods of judging the value of resources, strategies and markets appeared flawed, individuals with general business acumen who could project an image of mastery and control were highly valued. In this sense, the Zeitgeist produced metaopportunities which seemed to have little to do with either given opportunities for profit (Shane and Venkataraman, 2000) or the ambition to create (Sarasvathy, 2001).

There is of course nothing inherently wrong in trusting or investing in individuals who appear able to read trends. Such principal-agent relations are inherent in any entrepreneurial process and, since the rewards of an opportunity are always reaped in the uncertain future, VCs and others to some extent always invest in the capacity to envision and enact that future (compare the adage 'we invest in people'). From a discovery perspective, such opportunism can be explained by changing the frame of reference. If opportunities are not judged from the baseline of future market success, but against the backdrop of personal profit maximizing (cf. Douglas and Shepherd, 2000), the opportunities can again be said to exist objectively. From a creativity perspective, the explanation would be rather different. Since the future is not only unknown but in important ways unknowable, there can be nothing solid on which to base evaluations, except socially negotiated opinions and investments in people who, one believes, are on 
top of developing trends (Lane and Maxfield, 1996). Since entrepreneurship is seen as a social endeavor where new realities, in the form of markets, products, behaviors etc., are created by entrepreneurs (Sarasvathy, 2004), it is impossible to control and delimit potential hypes and bubbles in advance. Instead, the creation perspective would see bubbles and opportunistic behavior as natural occurrences, and even as testimony to the genuinely social character of human action. It is interesting to note that the entrepreneurs also reflexively relied on their own ability to embody the Zeitgeist when making important decisions, for instance by using and trusting themselves as evaluative tools vis-à-vis opportunities, e.g. through the sense of excitement they felt about a new product idea.

Stability as strategy reflects a general approach of seeking out a place which one believes to be secure. Such stability can be found in many different dimensions of a venture, such as reliable personnel, a clear business idea, or an extreme focus on customer value. To strategically stay clear of perceived uncertainties and short-term hypes, and instead establish a stable foundation, may also foster focused learning and yield economies of specialization, something which can prove to be very valuable in a turbulent industry. This strategy can be interpreted as uncertainty management through the execution of a well-crafted plan (Shane, 2003). However, it may also be interpreted as an incremental development strategy focusing on organic growth and learning based on available resources (Sarasvathy, 2001).

Sequential entry process shows how entrepreneurs strategically seek to manage the uncertainties of future entrepreneurial opportunities. The previous factors focused mainly on enacting or avoiding uncertainty. Sequential entry process describes different ways of strategically positioning oneself to reap the benefits of what is perceived as an uncertain but very lucrative future. Typically entrepreneurs seek to survive the turbulent present, and simultaneously prepare to act on opportunities envisioned in the future. This resembles a real options strategy in that entrepreneurs can defer vital decisions until a less uncertain future. The real options analogy, however, is problematic in the face of genuine uncertainty where the value of the option/opportunity can be affected by the entrepreneur (Adner and Levinthal, 2004). The sequential entry process may therefore also be interpreted as strategic development of generative relationships (Lane et al. 1996). By consulting, initiating collaborations, developing customer relations etc., the entrepreneurs are shaping future conditions and thereby actively creating their opportunities (Sarasvathy, 2001). 
The discussion shows that both theoretical perspectives resonate with different aspects of opportunities as experienced by entrepreneurs. They do not, however, separate the empirical factors in any decisive way, as all factors could to some extent be interpreted in the light of both perspectives. The factors Filling the gap, Opportunity in timing and also Exploiting knowledge seemed somewhat more amenable to the discovery perspective. Here, entrepreneurial opportunities were described as existing in the potential to transfer an idea from one context to another, in asynchronous timing of events, and in using one's position and knowledge to connect different technologies and markets. But these categories also showed that opportunities are sometimes passively called forth by the social environment, and that the environment for opportunities can be fundamentally affected by socially created timeframes. The three remaining factors were closer to the creation perspective. Enacting the Zeitgeist, Stability as strategy and Sequential entry process describe opportunities in more vague terms as existing in the remote future. Instead of exploitation processes, these categories speak of open possibilities and strategies to keep the venture in business, refine the business idea, and generally position the venture for an uncertain future. See Table 3 for a brief recapitulation of this point.

Table 3. Examples of Discovery and Creation in the Empirical Factors. Shaded Areas Indicate Whether Emphasis is on Discovery or Creation.

\begin{tabular}{|l|l|l|l|l|l|l|}
\hline & $\begin{array}{l}\text { Exploiting } \\
\text { knowledge }\end{array}$ & $\begin{array}{l}\text { Filling the } \\
\text { gap }\end{array}$ & $\begin{array}{l}\text { Opportunity } \\
\text { in timing }\end{array}$ & $\begin{array}{l}\text { Enacting the } \\
\text { Zeitgeist }\end{array}$ & $\begin{array}{l}\text { Stability as } \\
\text { strategy }\end{array}$ & $\begin{array}{l}\text { Sequential } \\
\text { entry process }\end{array}$ \\
\hline \multirow{5}{*}{ Discovery } & $\begin{array}{l}\text { Exploiting } \\
\text { knowledge of } \\
\text { technologies } \\
\text { and markets }\end{array}$ & $\begin{array}{l}\text { Filling gaps } \\
\text { in the } \\
\text { structural } \\
\text { environment }\end{array}$ & $\begin{array}{l}\text { Identifying } \\
\text { asynchronous } \\
\text { processes }\end{array}$ & $\begin{array}{l}\text { Predicting } \\
\text { megatrends }\end{array}$ & $\begin{array}{l}\text { Strategic } \\
\text { management } \\
\text { of risk and } \\
\text { uncertainty }\end{array}$ & $\begin{array}{l}\text { Strategic } \\
\text { positioning } \\
\text { as a real } \\
\text { option }\end{array}$ \\
\hline \multirow{6}{*}{ Creation } & $\begin{array}{l}\text { Expert } \\
\text { entrepreneurs } \\
\text { pulled forth } \\
\text { by external } \\
\text { actors }\end{array}$ & $\begin{array}{l}\text { Adjusting } \\
\text { and } \\
\text { translating } \\
\text { existing } \\
\text { solutions }\end{array}$ & $\begin{array}{l}\text { Opportunities } \\
\text { emerging in } \\
\text { socially } \\
\text { created } \\
\text { time- } \\
\text { bubbles }\end{array}$ & $\begin{array}{l}\text { Visceral } \\
\text { interpretations } \\
\text { and meta- } \\
\text { opportunities } \\
\text { residing in } \\
\text { the hype }\end{array}$ & $\begin{array}{l}\text { Incremental } \\
\text { development } \\
\text { departing } \\
\text { from local } \\
\text { situations }\end{array}$ & $\begin{array}{l}\text { Opportunity } \\
\text { creation by } \\
\text { strategically } \\
\text { leveraging } \\
\text { relationships }\end{array}$ \\
\hline
\end{tabular}

As can be seen, none of the empirical factors fits neatly into either theoretical perspective. Instead it seems that opportunity is a quite broad concept that receives its meaning along a variety of more or less tangible dimensions. Seen in this way, the current study suggests that the phenomenological validity of both the discovery and creation perspectives is limited. The results also suggest some interesting implications concerning the relationship between opportunity perception and entrepreneurial ac- 
tion. When seen as part of a richer 'phenomenology of opportunity' the two perspectives can be brought together in a more comprehensive framework that connects opportunity perception to entrepreneurial action. The concluding section will therefore take a cue from the above results and depart from the debate about the discovery and creation of opportunities, to discuss how entrepreneurs' varied experiences of opportunities may act as drivers of entrepreneurial action.

\section{CONCLUSIONS}

As seen above, both the discovery and creation perspectives could be used to make theoretical sense of parts of the results. Conceptualizing opportunities as existing and created also corresponds to many process theories of creativity and innovation where an initial period of openness and creative expansion is followed by a period of closure and more focused work (Nyström, 1979, Csikszentmihalyi, 1996, Lumpkin et al. 2003). As a venture grows and matures, this description may to some extent be quite true. However, this study did not address such temporal dynamics but focused on the richness of opportunities as experienced and perceived. From this perspective, the findings suggest that entrepreneurs have a broad and multifaceted view of opportunities as related to abstract megatrends, availability of venture capital, and gut feelings - as well as to more clearly perceived market needs, industry bottlenecks and inherent technological potential. While such categories to different degrees lend themselves to the discovery and creation perspectives, they should not be seen as corresponding directly either to different theoretical perspectives or, perhaps more importantly, to underlying kinds of opportunities. Instead, the categories and factors should be understood, in a holistic perspective, as reflecting the multitude of ways in which the same person or group experiences opportunities as part of the venture development process. This also means that the different categories are not mutually exclusive descriptions of how opportunities are perceived, but provide different angles and perspectives on a rather complex phenomenon.

One way to make sense of the rich and varied ways in which opportunities are perceived is by relating these perceptions to entrepreneurial action. Specifically, the wide range of opportunity perceptions may provide insight into how opportunity perceptions act as drivers of entrepreneurial action. It has long been acknowledged that the way opportunities are understood and experienced will influence what actions are taken (cf. 
Krueger, 2000). Therefore, perceiving an opportunity as existing, e.g. in the sense of asynchronous processes or a structural gap, or as being created, e.g. viscerally sensed or seen as the potential outcome of social collaborations, will provide different cues or focal points for entrepreneurial action. Entrepreneurial action can thus be seen as driven forward by a range of more or less temporary perceptions of 'real' opportunities as well as less clear visions and ideas of a future not yet created.

Opportunity perceptions may also be used strategically to serve different purposes, e.g. in relation to customers, venture capitalists, employees, and reflexively the entrepreneur him/herself. A key to improving our understanding of entrepreneurial opportunities may therefore be found in the ways they are actively described and promoted in specific situations. Opportunities may, for instance, be described as existing for purposes like legitimizing the venture to potential customers, and as a way to focus work and get different people to pull in the same direction. Seeing opportunities as mutable and under construction can similarly be useful for legitimizing inter-firm cooperation, and for encouraging creativity and an experimental attitude among employees. This view echoes evolutionary theories of organizational creativity where "customizing one's "sales pitch" (Ford 1996: 1133), and projecting more or less concrete images of an innovation in different social domains, is seen as a vital driver of individual creative action. Continuing the evolutionary metaphor, entrepreneurs may develop their ventures by comparing and contrasting the variety of ways in which opportunity projections are received in different situations.

This brief exploration suggests that future research may benefit from theorizing entrepreneurial opportunities in relation to entrepreneurial action. Instead of elaborating opportunity discovery and creation as isolated theoretical perspectives, it seems fruitful to view opportunities in terms of a bundle of perceptions and projections which, in different ways and in different situations, influence venture development. This may seem a bit incoherent. However, if the purpose is not primarily to build ontologically consistent models, but to understand real-life action, this kind of ambivalence should not be seen as a theoretical problem but as a pragmatic asset. To quote Weick: "People who study sensemaking oscillate ontologically because that is what helps them understand the actions of people in everyday life who could care less about ontology" (Weick 1995: 35). A suitable way of conceiving opportunities is therefore not as either existing or created per se, but as a bundle of more or less clear opportunity perceptions and opportunity projections that become relevant in a variety of situations and for a number of different reasons. It is in this multifaceted role that 
opportunities are truly relevant, since acting as if opportunities are both existing and created provides the cognitive and practical drivers that guide entrepreneurial actions.

\section{FOODNOTES}

1 Besides his work on sociology and social phenomenology, Schütz collaborated with Hayek, Mises and other early subjectivist economists. The original quotation reads: "The answer to the question 'what does this social world mean for me the observer?' requires as a prerequisite the answering of the quite other questions 'what does this social world mean for the observed actor within this world, and what did he mean by his acting within it?" (Schütz 1940, p. 48).

2 This quotation borrows heavily from Casson (2003) who is also referenced by Shane and Venkataraman (2000).

\section{REFERENCES}

Adner, R. and Levinthal, D. (2004). What is not a Real Option: Identifying Boundaries for the Application of Real Options to Business Strategy. Academy of Management Review. 29(1): 74-85.

Ardichvili, A. amd Cardozo, R. (2003). A model of the entrepreneurial opportunity recognition process. Journal of Enterprising Culture. 8(2): 103-119.

Baron, R. (2004). The Cognitive Perspective: A Valuable Tool for Answering Entrepreneurship's Basic “Why" Questions. Journal of Business Venturing. 19(2): 221-239.

Benner, P. (ed.) (1994). Interpretive Phenomenology: Embodiment, Caring and Ethics in Health and Illness. Thousand Oaks, CA: Sage.

Berglund, H. (2007). Researching Entrepreneurship as Lived Experience. In J. Ulhoi and H. Neergaard (eds.), Handbook of Qualitative Research Methods in Entrepreneurship, pp. 75-93. Edward Elgar.

Bhave, M. P. (1994). A Process Model of Entrepreneurial Venture Creation. Journal of Business Venturing. 9: 223-242.

Buchanan, J. and Vanberg, V. (1991). The Market as a Creative Process. Economics and Philosophy. 7: 167-186.

Burt, R. (2000). The Network Entrepreneur. In R. Swedberg (ed.), Entrepreneurship: A Social Science View, pp. 281-307. Oxford: Oxford University Press.

Busenitz, L. amd Barney, J. (1997). Biases and Heuristics in Strategic Decision-making: Differences between Entrepreneurs and Managers in large organizations. Journal of Business Venturing. 12(1): 9-30.

Bygrave, W. and Hofer, C. (1991). Theorizing about Entrepreneurship. Entrepreneurship Theory and Practice. 16(2): 13-2.

Casson, M. (2003). The Entrepreneur: An Economic Theory. Cheltenham: Edward Elgar. 
Chiasson, M. and Saunders, C. (2005). Reconciling diverse approaches to opportunity research using the structuration theory. Journal of Business Venturing. 20(6): 747767.

Csikszentmihalyi, M. (1996). Creativity: Flow and the Psychology of Discovery and Invention. New York: Harper Collins.

Cyert, R. and March J. (1963). A Behavioral Theory of the Firm. Englewood Cliffs, NJ: Prentice Hall.

Davidsson, P. (2004). Researching Entrepreneurship. New York: Springer.

Delmar, F. and Shane, S. (2003). Does Business Planning Facilitate the Development of New Ventures? Strategic Management Journal. 24(12): 1165-1185.

Delmar, F. and Shane, S. (2004). Legitimating First: Organizing Activities and the Survival of New Ventures. Journal of Business Venturing. 19(3): 385-410.

DeTienne, D. and Chandler, G. (2004). Opportunity Identification and its role in the Entrepreneurial Classroom: A Pedagogical Approach and Empirical Test. Academy of Management Learning and Education. 3(3): 242-257.

Douglas, E. and Shepherd, D. (2000). Entrepreneurship as a Utility-Maximizing Response. Journal of Business Venturing, 15(3): 231-251.

Drucker, P. (1985). Innovation and Entrepreneurship: Practice and Principles. New York: Harper \& Row.

Fiet, J. (1996). The informational Basis of Entrepreneurial Discovery. Small Business Economics. 8, 419-430.

Ford, C. (1996). A Theory of Individual Creative Action in Multiple Social Domains. Academy of Management Review. 21(4): 1112-1142.

Gaglio, C. and Katz, J. (2001). The Psychological Basis of Opportunity Identification: Entrepreneurial Alertness. Journal of Small Business Economics. 16: 95-111.

Gartner, W., Bird, N. amd Starr, J. (1992). Acting as if: Differentiating entrepreneurial from organizational behavior. Entrepreneurship: Theory \& Practice. 16(3): 13-31.

Gartner, W., Carter, N. amd Hills, G. (2003). The Language of Opportunity. In C. Steyaert and D. Hjorth (eds.), New Movements in Entrepreneurship, pp. 103-124. Cheltenham, UK: Edward Elgar.

Gartner, W., Shaver, K. and Katz, J. (1994). Finding the Entrepreneur in Entrepreneurship. Entrepreneurship Theory and Practice, 18(3): 5-1.

Giorgi, A. (1985). Phenomenology and psychological research. Pittsburgh: Duquesne University Press.

Hayek, F. (1937). Economics and knowledge. Economica. 4:33-54.

Hayek, F.A. (1945). The Use of Knowledge in Society. American Economic Review. 35(4): 519-530.

Helltröm, T., Hellström, C. and Berglund, H. (2002). The Innovating Self - Exploring Self among a Group of Technological Innovators. Journal of Managerial Psychology. 17(4): 267-286.

Herron, L. and H. Sapienza (1992). The Entrepreneur and the Initiation of New Venture Launch Activities. Entrepreneurship Theory \& Practice. 17(1): 49--55.

Johannisson, B. (2000). Networking and Entrepreneurial Growth. In Sexton, D. \& Landström, H. (eds.), Handbook of Entrepreneurship, pp. 368-386. London: Blackwell.

Kaish, S. and Gilad, B. (1991). Characteristics of Opportunities Search of Entrepreneurs Versus Executives: Sources, Interests and General Alertness. Journal of Business Venturing. (6): 45-61. 
Kirzner, I. (1973). Competition and Entrepreneurship. Chicago and London: University of Chicago Press.

Kirzner, I. (1985). Discovery and the Capitalist Process. Chicago: University of Chicago Press.

Kirzner, I. (1992). The Meaning of Market Process: Essays in the development of modern Austrian economics. London: Routledge.

Krueger, N. (2000). The cognitive infrastructure of opportunity emergence. Entrepreneurship: Theory \& Practice. 24(3), 5-23.

Lachmann, L. (1976). From Mises to Shackle: An essay on Austrian economics and the kaleidic society. Journal of Economic Literature. 14(1): 54-62.

Lane, D. and Maxfield, R. (1996). Strategy under Complexity: Fostering Generative Relationships. Long Range Planning. 29, 215-231.

Lane, D., Malerba, F., Maxfield, R. and Orsenigo, L.. (1996). Choice and Action. Journal of Evolutionary Economics. 6, 43-76.

Lavoie, D. (1991). The Discovery and Interpretation of Profit Opportunities: Culture and the Kirznerian Entrepreneur. In B. Berger (ed.), The Culture of Entrepreneurship. San Francisco: ICS Press.

Lindblom, C.E. (1959). The Science of 'Muddling Through'. Public Administration Review, 19(2): 79-88.

Littlechild, S. (1986). Three Types of Market Process. In Langlois, R. (ed.), Economics as a Process. Cambridge: Cambridge University Press.

Lumpkin, G. T., Hills, G. E. and Shrader, R.C. (2003). Opportunity Recognition. In Harold P. Welsch (ed.), Entrepreneurship: The Way Ahead. New York: Routledge.

Merleau-Ponty, M. (2002). Phenomenology of Perception. London: Routledge.

Mises, L. (1996). Human Action: A Treatise on Economics. Fourth revised edition. San Francisco: Fox \& Wilkes. Available at www.mises.org.

Nelson, T. ( 2003). The Persistence of Founder Influence: Management, Ownership, and Performance Effects at Initial Public Offering. Strategic Management Journal. 24(8): 707-724.

Nyström, H. (1979). Creativity and Innovation. New York: Wiley.

Rothbard, M. (1992). How and How Not To Desocialize. The Review of Austrian Economics. 6(1): 65-77.

Saks, N. and Gaglio, C. (2002). Can Opportunity Identification be Taught? Journal of Enterprising Culture. 10(4): 313-347.

Sarasvathy, S. (2001). Causation and Effectuation: Toward A Theoretical Shift from Economic Inevitability to Entrepreneurial Contingency. Academy of Management Review, 26(2): 243-288.

Sarasvathy S. (2004). Constructing Corridors to Economic Primitives: Entrepreneurial Opportunities as Demand-Side Artifacts. In J. Butler (ed.), Opportunity Identification and Entrepreneurial Behavior, pp. 291-312. Greenwich CN: Information Age Publishing.

Sarasvathy, S. (2006). Effectuation: Elements of Entrepreneurial Expertise. Cheltenham, UK: Edward Elgar

Sararvathy, S., Dew, N. Velamuri, R. and Venkataraman, S. (2003). Three views of entrepreneurial opportunity. In Z. Acs and D. Audretsch (eds.), Handbook of Entrepreneurship, pp. 141-160. Boston, MA: Kluwer. 
Sarasvathy, D., Simon H.. and Lave, L. (1998). Perceiving and Managing Business Risks: Differences Between Entrepreneurs and Bankers. Journal of Economic Behavior and Organization. 33, 207-225.

Schultz, T. (1980). Investment in Entrepreneurial Ability. Scandinavian Journal of Economics. 82(4): 437-448.

Schumpeter, J. (1961). The Theory of Economic Development. Cambridge, MA: Harvard University Press. New York: Oxford University Press.

Schumpeter, J. A. (1975). Capitalism, Socialism and Democracy. New York: Harper.

Schütz, A. (1940). Parsons' Theory of Social Action: A Critical Review by Alfred Schütz. In Grathoff (ed.) (1978), The Theory of Social Action: The Correspondence of Alfred Schütz \& Talcott Parsons, pp. 8-124. Bloomington: Indiana University Press.

Shackle, G. (1979). Imagination and the Nature of Choice. Edinburgh: Edinburgh University Press.

Shackle, G. (1988). Introduction. In Hébert, R. \& Link, A. The Entrepreneur Mainstream Views and Radical Critiques, $2^{\text {nd }}$ edition, pp. ix-xi. New York: Praeger.

Shane, S. (2000). Prior Knowledge and the Discovery of Entrepreneurial Opportunities. Organization Science. 11(4): 448-469.

Shane, S. (2003). A General Theory of Entrepreneurship: The Individual-Opportunity Nexus. Aldershot: Edward Elgar.

Shane, S. and Venkataraman, S. (2000). The Promise of Entrepreneurship as a Field of Research. Academy of Management Review, 25(1): 217-226.

Shining Stockholm (2000, February 7). Newsweek International.

Simon, H. (1993). Altruism and economics. The American Economic Review. 83(2): 156161.

Smith, J. A. (1996) Beyond the Divide between Cognition and Discourse: using Interpretative Phenomenological Analysis in Health Psychology. Psychology \& Health. 11, 261-271.

Stake, R. (1994). Case studies. In N. K. Denzin and Y. S. Lincoln (eds.), Handbook of qualitative research. (236-247). Thousand Oaks, CA: Sage Publications.

Stevenson, H. and Jarillo, J. (1990). A Perspective of Entrepreneurship: Entrepreneurial Management. Strategic Management Journal. 11: 17-27.

Steyaert, C. and Katz, J. (2004). Reclaiming the Space of Entrepreneurship in Society: Geographical, Discursive and Social Dimensions. Entrepreneurship and Regional Development. 16(3): 179-196.

The Race to Rule Mobile (2000, February 21). Business Week International.

Van Gelderen, M. (2004). A Framework for Conjecturing Entrepreneurial Opportunities: An Application to Individualization of Demand in the Undertaking Business. Journal of Enterprising Culture. 12(4): 351-371.

Van Manen, M. (1990) Researching lived experience: Human science for an action sensitive pedagogy. Albany, NY: State University of New York Press.

Weick, K. (1995). Sensemaking in Organizations. Thousand Oaks, CA: Sage.

Venkataraman, S. (1997). The Distinctive Domain of Entrepreneurship Research. In J. Katz (ed.), Advances in Entrepreneurship, Firm Emergence and Growth, Vol. 3, pp. 119-138. Greenwich, CT: JAI Press. 